\title{
THE APPLICATION OF SURVEY IN ER WANG TEMPLE RESTITUTING
}

\author{
Wang Shuai ${ }^{\text {a }}$, Zhang Rong ${ }^{\mathrm{b}}$
}

\begin{abstract}
${ }^{a}$ School of Architecture, Tsinghua university, No.1 Tsinghua yuan, Haidian Dist., Beijing, China - wangshuai@chcc.org.cn ${ }^{\mathrm{b}}$ Cultural Heritage Conservation Center, Tsinghua Tongheng Urban Planning \& Design Institute, No.8 Zhongguancun East Road, Haidian Dist., Beijing, China - zhangrong@ chcc.org.cn
\end{abstract}

KEY WORDS: The stage in Er Wang Temple, Survey, 3D laser scanning, Site exploration, Residual components

\begin{abstract}
:
Er Wang Temple, in World Heritage Site "Dujiang Weirs and Qingchengshan Mountain”, was severely destroyed in Wenchuan earthquake of May 2008. There are several problems at different level in every building, such as structural distortion, foundation displacement, wall fracture, roof damage, etc. The stage was completely collapsed in the earthquake. Tableland the stage situated had a huge crack and slope collapse. This article is for the stage renovation. The survey of damage in earthquake is the basis of Er Wang Temple restituting. Survey including field survey after the earthquake and the measurement and investigation for the remained construction member of the main wood structure. For field survey, the basis of pillars which had not have significantly affects in earthquake could be seem as the reference points for measurement. The investigation of remained main wood construction member, especially the size of the key structures and site and manufacture method of the joints, is the important basis for recovery stage.

Our team did our utmost to restore the original appearance of stage in design, materials and craft by various tools, which include measured drawings in different times, old images collection, fine measuring by $3 \mathrm{D}$ laser scan, measurement of leftover pieces, logical inference.
\end{abstract}

\section{PROJECT OVERVIEW}

\subsection{Introduction of Er Wang Temple}

Er Wang Temple is located in the northwest of downtown Dujiangyan, along the eastern coast of Minjiang inner river, at the foot of Lingyanshan Mountain. Er Wang Temple, in World Heritage Site "Dujiang Weirs and Qingchengshan Mountain" elected on November 29, 2000, is the most important part. Er Wang Temple is in memory of the related people who constructed the water conservancy project in Dujiang Weirs by local people, it has a great influence in the whole Sichuan province. Er Wang Temple had repeatedly suffered from disaster in history, but repeatedly destroyed repeatedly constructed, and it continues today.

The stage is located in the center of the central axis of Er Wang Temple, is the main door of the main shrine. This building have two functions, the gate and the stage. In addition, the structure of the stage is exquisite, and the modelling of the roof is full of novelty and complexity. In short, it plays a very important role in the Er Wang Temple. The stage buildings are made up of the stage, East-West Corridor, the east sitting room and west guest room. (Photo 1,2)

According to historical records, the stage buildings were built in Kangxi forty-fifth year (AD 1706). But according to the study on the historical evolution of Er Wang Temple, the stage at that time could be the reconstruction of the gate to the temple. Since the Kangxi period to the late Qing dynasty, Er Wang Temple suffered from disaster at least once, resulting in reconstruction of a large number of halls, but it is unknown if the stage had been destroyed and rebuild that time.

Er Wang Temple suffered from a fire in 1925, the stage has been destroyed, leading to the reconstruction of the stage after
1927. And then the stage buildings remained before Wenchuan earthquake

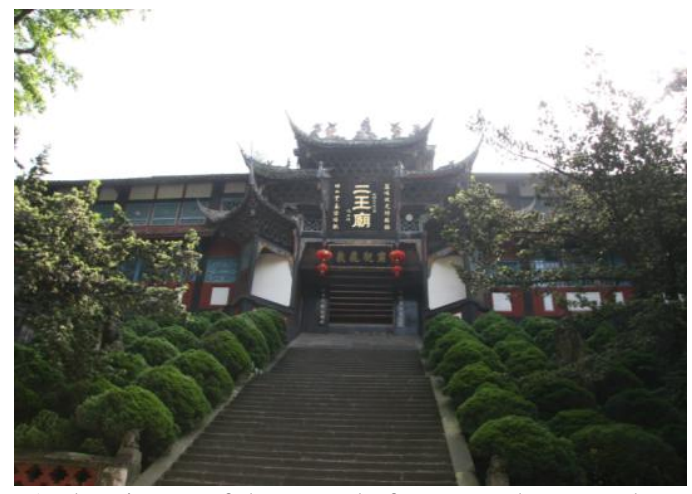

Photo 1.The picture of the stage before Wenchuan earthquake

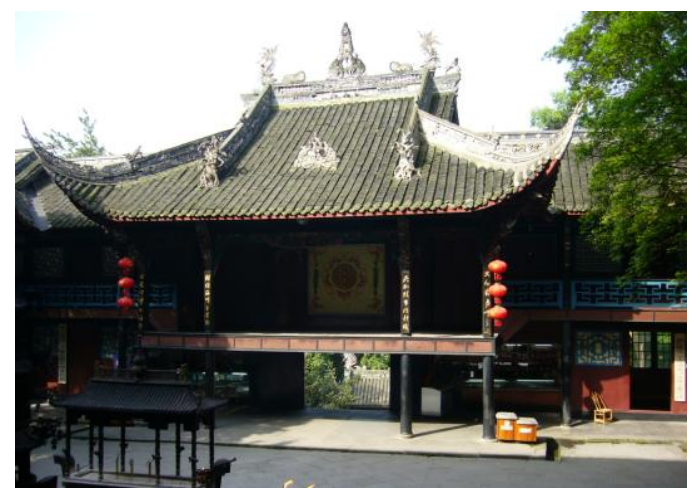

Photo 2.The north facade of the stage 


\subsection{Project Context}

Er Wang Temple was severely destroyed in Wenchuan earthquake in May 2008. There are several problems at different level in every building, such as structural distortion, foundation displacement, wall fracture, roof damage, etc. The stage was completely collapsed in the earthquake. Tableland of the stage situated had a huge crack and slope collapse.

Based on the regional stratigraphic data and geological prospecting results, Jiangyou-Guanxian big fracture traverse Er Wang Temple ancient sites. This region is also referred to as the Er Wang Temple fracture, the overall trend is $30 \sim 60^{\circ}$, section tendency $310 \sim 330{ }^{\circ}$, inclination $45 \sim 53^{\circ}$. Due to affection by the fracture structure, extrusion rupture and distortion has obvious deformation in the bedrock. It not only destroyed the integrity of rock mass, and made groundwater actively. In addition, Er Wang Temple is located in the Longmen mountain seismic belt, where was a high frequency and the meizoseismal area in earthquake.

Wenchuan earthquake is the main reason of Er Wang Temple's serious damage. Especially Er Wang Temple fault zone through Er Wang Temple architectural complex appeared greatly dislocation, causing serious damage to the mountain and buildings. On the other hand, because of the rough foundation of the additional buildings constructing in later period, artificial platform collapsed in the quake, causing buildings on it have been destroyed.

Stage is located in the southeast of the main shrine. The earth's surface dislocation in this area, cracking and uneven settlement of foundation, artificial platform and building foundation collapse, result in the stage and both sides of the corridors and the east sitting room collapsed in the quake, the west guest room roof destruction and structural deformation. It is a group of buildings suffering the most serious earthquake damage in $\mathrm{Er}$ Wang Temple. (Photo 3)

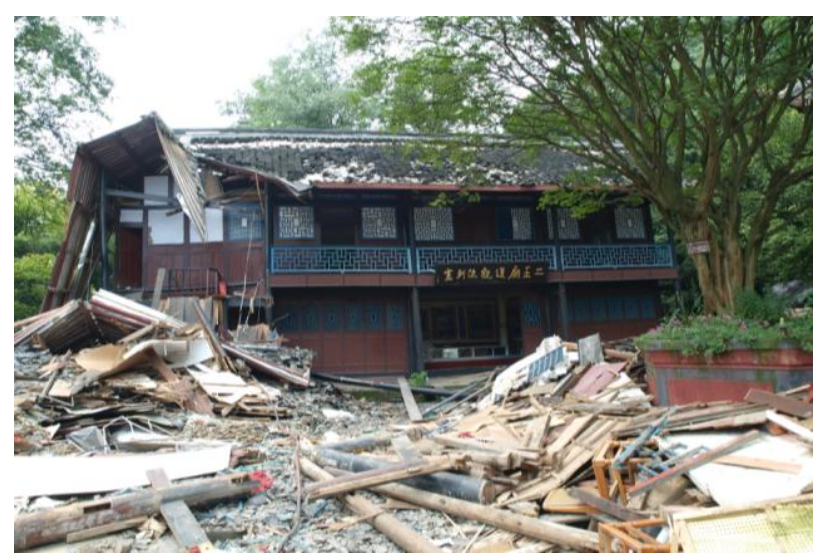

Photo 3. The picture of west guest room after the earthquake

\section{FIELD INVESTIGATION AFTER THE QUAKE}

In order to rebuilt the stage and on both sides of the corridors, the east sitting room, to repair the west guest room, except for residual west guest room to do surveying and mapping, still need to do detailed survey, sorting the buildings' residual compoments after the earthquake. Damage data after the earthquake of ancient buildings' timber compoments has high scientific research value, such as the fractured components, the collapsed walls, the deformational stylobates, the crooked pillars, oblique and torsional beams, the split or fractured mortise and tenon joint, sliding tile roof. They reflect each weak parts of the ancient buildings on the structure and existing problems, and it is first-hand scientific and technical material, containing a large number of information on science and technology. In 5.12 Wenchuan earthquake, the ancient architectural complexes of Er Wang Temple suffered from devastating damage. Continuous aftershocks and frequent rainfall also brought a lot of difficulties to field investigation after the earthquake, as well as the existing cultural relics of the cleaning, collection and saving. Therefore, how to record the site information rapidly, comprehensive and accurately, is the first step to restore the stage buildings.

\subsection{Site exploration after the quake}

3D laser scanning survey is a new type of surveying method with a variety of high and new technology, it uses tens of thousands to hundreds of thousands of points per second to laser scanning surfaces in high speed, getting 3D laser space information from object surface, and manifesting in the form of point cloud. According to difference between long range and short range of scanners, the scanning accuracy is between 0.008 $\mathrm{mm}-3 \mathrm{~mm}$. 3D laser scan can meet the needs of objects from different distance, with features of high speed, no contact, wide range, high precision, etc.

The stage were completely disrepair in the earthquake, and the southeast corner of the ground partly disrepair. We use 3D laser scanning to survey the existing site, five plinths are not affected apparently by the earthquake and remained, they are located in the northeast corner of the stage and the west corridor. By observing, each plinth carved small hole in the central location. Basing on this hole, we measure the existing plane data.

This scan for the stage field measurement has also carried on the plane elevation measurement. Made the northwest corner of the stage as the basis, we measured the elevation of object remained of the stage, such as plinths, and ground plane (including the collapsing ground affected by the earthquake), and drains etc... According to analysis of stage terrain deformation data after the quake based on 3D laser scanning, we could clearly understand the scope and degree of the southeast corner of foundation subsidence, we could also clearly see the original position of plinths on 3D model. With detailed terrain drawings by scanning, the graphic data and ground elevation data provides reference for the restoration of the stage. (Figure 1)

\subsection{Data Investigation before the earthquake}

With field investigation at the same time, we also collected the stage buildings data before the earthquake to help architecture restoration. Survey map of the stage and corridors mainly relies on the surveying information before the earthquake. There are measured drawings of the stage and both sides of the corridors in 2003 and 2004, and the survey map by school of Architecture, Tsinghua University for the stage in April 2008, and survey map in Chongqing University master's degree thesis Studies of Er Wang Temple in 2005 cited the drawing from Sichuan ancient architecture design institute. After compared with the original images and the local people identification, survey map from 2003 to 2004 is the closest object to its original state. So we took it as the most direct reference and the rest of the two drawings as a reference.

In order to improve the authenticity of constructions, collecting old photos of the buildings is also necessary. The original photo collection is divided into two kinds: one kind is the photos by School of Architecture, Tsinghua University when they surveyed in April 2008; The other kind is the historical 


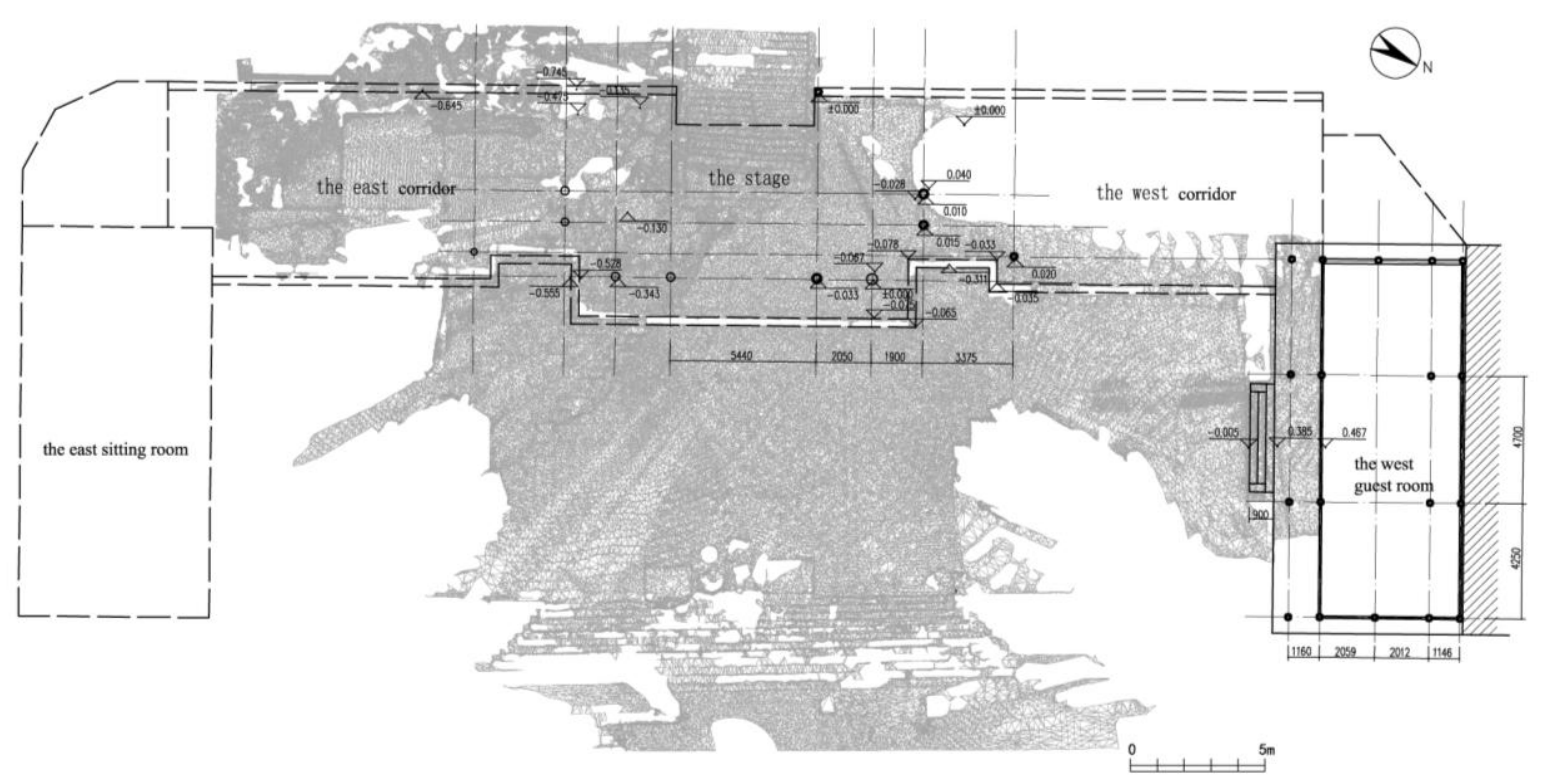

Figure 1. 3D laser scanning for the stage site

photographs, including online photos collection, the pictures in the books, as well as related photos provided by local cultural relics conservation institutions.

\subsection{Residual components' survey}

In addition to a survey of existing venues, we also in survey of the residual compoments of main wooden structure after the quake in the stage, corridors and the east parlour, investigation content is as follows:

1. Measure all the dimensions of the components, and mark on the components in order to find easily.

2. According to the shape, size of components and the primitive location components caved in, combining with survey map before quake and retained component size we could approximately judge whether components belonged to the stage buildings.

3. Then we classified the retained components belonged to the stage buildings by type (such as girders and pillars, plinths, purlins, etc.) (Photo 4). According to the location of the mortise and tenon joints on the components, we could roughly judge components belonged to which part of the building. Contrast with the existing components' size data and the original survey map, we tried to get more detailed data, in order to support the recovery work.

4. After the classification of the components, we judged the damage degree and the strength of the components. Then the components could be divided into the following three categories: Almost intact components (components which can be used directly in the recovery project); Local damaged components (components which may continue to be used by strengthening and maintenance) (Photo 5); Damaged seriously components (components which can't continue to be used, but can served as a basis for components replication). Retain the components which are unable to identify the location, so as to judge and use again in the construction process in the future.

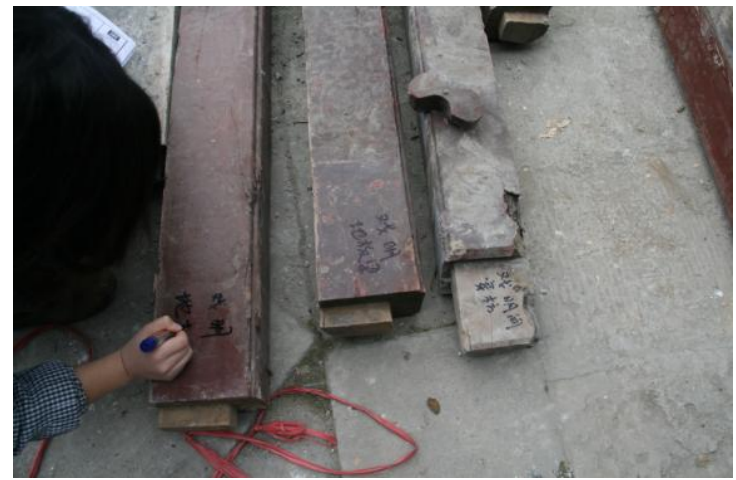

Photo 4. Classification of the components by type

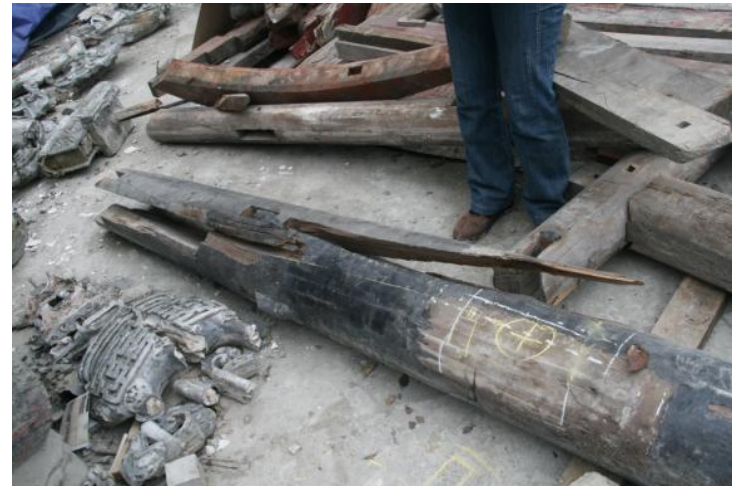

Photo 5. The component which may continue to be used by strengthening and maintenance

Intact components in the stage buildings are little, most of them are the connection components, such as fang, LouLeng, the main load-bearing components all have suffered from damage in different degrees, like pillars, girders, purlins, etc. The familiar damage are splitting, which locations are almost at the mortise and tenon joints which is connected with other components. Bug infestation phenomenon is relatively common. According to the damage degree and the location, we remained more components and strengthened and maintained them to be 
used in repair project, as much as we can to retain the more original components. The size of the key structure components such as pillars and girders of the stage and the positions of mortise and tenon joints are important basis to the stage buildings' restoration, such as pillar Z01-04 (Figure 2), girder L01-03 are the direct basis of the stage structure elevation and chapiters distance.

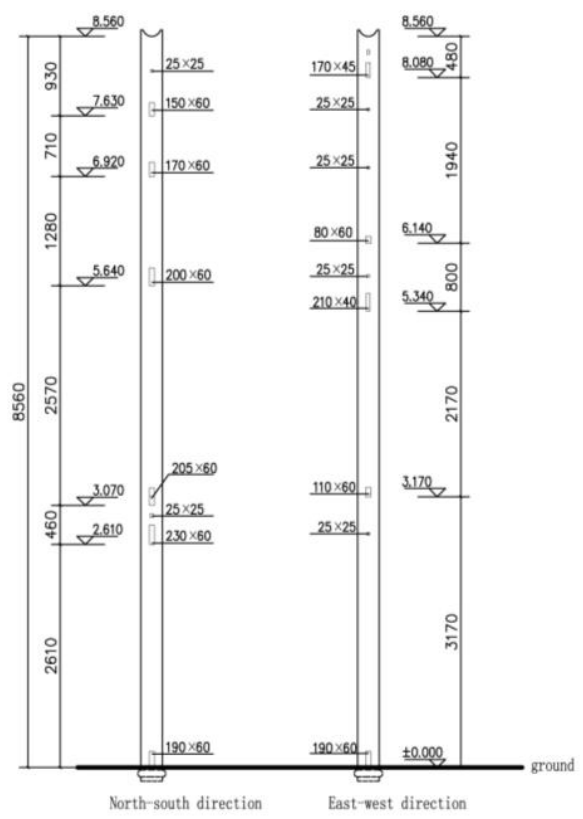

Figure 2. The survey map of the center pillar of the stage

\subsection{Inference for the size of the stage buildings}

According to the field survey (plinths distribution) and the survey results, adding the original survey map, we could calculate the stage buildings' Construction Ruler - - Building module in the Qing dynasty.

After comparison, integrated layout of the stage fit " Qing Gong $\mathrm{Bu}$ Gong Cheng Zuo $\mathrm{Fa}$ ", using Chi and Cun (units of measurement in ancient China, 1chi=10cun) as the basic units to carry on the design and construction. By calculating ,the basic unit is: 1 Construction Ruler $(1 \mathrm{chi})=316 \mathrm{~mm}$, mostly the same as Construction Ruler in the Qing dynasty ( 1 chi=320 $\mathrm{mm})$.(Chart 1)

Chart 1: Measurement for the size of existing column grid

\begin{tabular}{|c|c|c|c|c|}
\hline & $\begin{array}{c}\text { Original } \\
\text { Size(mm) }\end{array}$ & $\begin{array}{c}\text { Calculated } \\
\text { size(cun) }\end{array}$ & $\begin{array}{c}\text { Speculated } \\
\text { size(cun) }\end{array}$ & $\begin{array}{c}\text { Speculated } \\
\text { data(mm) }\end{array}$ \\
\hline $\begin{array}{c}\text { Width of the } \\
\text { east room in } \\
\text { the stage }\end{array}$ & 2050 & 64.9 & 65 & 2054 \\
\hline $\begin{array}{c}\text { Width of the } \\
\text { west room } \\
\text { in the east } \\
\text { corridor }\end{array}$ & 1900 & 60.1 & 60 & 1896 \\
\hline $\begin{array}{c}\text { Half of } \\
\text { depth of the } \\
\text { stage }\end{array}$ & 3155 & 99.8 & 100 & 3160 \\
\hline
\end{tabular}

${ }^{1}$ Distance between the center pillar and the corner pillar

Through calculation we recognized that, width of the stage is thirty chi, depth is twenty chi, the east corridor's width is fifty chi, the width of the east parlour is forty-two chi, total depth is twenty chi. The stage and the total plane layout are very consistent with the Construction Ruler module.
Other buildings' depth, width and elevation which are belonged to the stage buildings are also consistent with the building module. The whole building's scale is neat, fitting with $316 \mathrm{~mm}$ as 1 Construction Ruler module system. It provides accurate standard for structure scale restoration of the stage. (Chart 2)

Chart 2: Speculated to the main data of the stage buildings

\begin{tabular}{|c|c|c|c|c|}
\hline & $\begin{array}{c}\text { Original } \\
\text { size(mm) }\end{array}$ & $\begin{array}{c}\text { Calculated } \\
\text { size(cun) }\end{array}$ & $\begin{array}{c}\text { Speculated } \\
\text { size(cun) }\end{array}$ & $\begin{array}{c}\text { Speculated } \\
\text { data(mm) }\end{array}$ \\
\hline $\begin{array}{c}\text { Width of } \\
\text { the stage }\end{array}$ & 9500 & 300.6 & 300 & 9480 \\
\hline $\begin{array}{c}\text { Depth of } \\
\text { the stage }\end{array}$ & 6450 & 204.1 & 200 & 6320 \\
\hline $\begin{array}{c}\text { Width of } \\
\text { the corridor }\end{array}$ & 15735 & 497.9 & 500 & 15800 \\
\hline $\begin{array}{c}\text { Width of } \\
\text { the east } \\
\text { sitting room }\end{array}$ & 13200 & 417.7 & 420 & 13272 \\
\hline $\begin{array}{c}\text { Depth of } \\
\text { the east } \\
\text { sitting room }\end{array}$ & 6377 & 201.8 & 200 & 6320 \\
\hline
\end{tabular}

The establishment of the system of module plays a role in size inference, especially providing the basis to determine the timber size in construction, plane size, the size of the facade layering. We used the module drawing a set of recovery construction drawings, compared with the size of the remaining components like depth, width, etc. Then we found that the size is nearly accurate. The location of the connected components can infer by the mortise and tenon joints' position of retained components.

\section{Conclusion}

Each period of the survey maps, old photos, 3D laser scanning for field precision measurement, measurement for residual components after an earthquake one by one, comparing with all kinds of information and logical reasoning, all of these provide conditions for us to looking for the buildings' historical trails before the quake from various angles. Through various technical means of survey and data analysis, we keep the authenticity on design, material, craft as much as possible in the reconstruction design, to recover the stage.

\section{References from Journals:}

Du Qiming, The discussion of main wood structure design modulus in Song Ying Zao $\mathrm{Fa}$ Shi. Ancient landscape technology, 1999,(4): 39 47

Yu Ming, Ding Chen, Guo Jingjun. 3D laser scanning technology on the study of ancient building surveying and mapping. Surveying and Mapping, 2004, 33(5): 69-70.

Zang Chunyu. The application of 3D laser scanning technology on the study of cultural heritage conservation. Architectural Journal, 2006, 12: 54-56

\section{References from Books:}

Cultural Heritage Conservation Center, Edit. Survey report of Er Wang Temple rescue and protection after the earthquake. 2010 